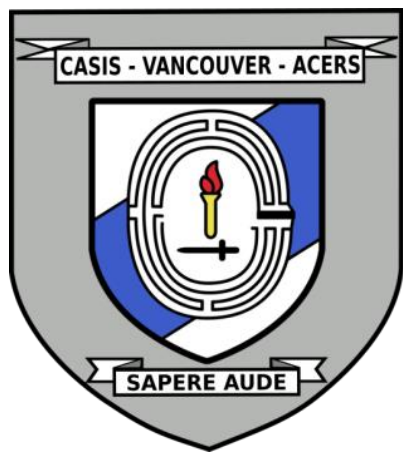

\title{
THE CHANGING NATURE OF INTELLIGENCE EDUCATION
}

Date: November 23, 2021

Disclaimer: This briefing note contains the encapsulation of views presented by the speaker and does not exclusively represent the views of the Canadian Association for Security and Intelligence Studies.

\section{KEY EVENTS}

On November 23, 2021, Dr. Stephen Marrin, program director at James Madison University, presented on The Changing Nature of Intelligence Education at the 2021 CASIS Vancouver West Coast Security Conference. This presentation was followed by a question and answer period and a breakout room session with questions from the audience and CASIS Vancouver executives. The key points discussed included the nature of intelligence studies, the importance of having diverse perspectives in the intelligence and national security space, and the importance of bridging gaps between scholars and practitioners.

\section{NATURE OF DISCUSSION}

\section{Presentation}

Dr. Marrin focused on some of the most important changes that have contributed to the growth of intelligence education, as well as the different ways to bridge the gap between scholars and practitioners in the intelligence space.

\section{Question Period}

During the question and answer period Dr. Marrin discussed the importance of diversity in the security space and the essential skills and/or traits that successful intelligence analysts must demonstrate when facing future asymmetric challenges and new security problems. 


\section{BACKGROUND}

\section{Presentation}

Dr. Marrin began his presentation by noting the changes he has seen over his thirty years of experience in intelligence education and how his personal experiences defined what he wanted to do to help analysts do a better job. To contextualize the discussion topic, Dr. Marrin characterized the nature of intelligence study as an interdisciplinary approach to a body of knowledge that is not intrinsically instrumental, which is partly because this body of knowledge can serve several purposes. For example, intelligence studies can historicize and theorize, such as covert operations during the Cold War and terrorism post 9-11.

One of the most prominent changes in the nature of intelligence is that the knowledge of intelligence studies has increased exponentially since the 1940's. Intelligence education relates to teaching about intelligence. For example, how knowledge about intelligence is taught in universities and how it is exercised in the real world, or how this knowledge transitions between theory and practice. Academic journals are great vehicles to enhance knowledge production of intelligence in the intelligence space. These journals facilitate the flow of good ideas, which allow others to study and learn from those ideas.

The expansion of the Intelligence Studies Section at the International Studies Association (ISA) has also contributed to the growth of intelligence studies. ISA is a large academic association, which brings together the voices of many academics, not only in journals and books but also through papers presented at their conferences. Conference presentations are the next stage in this knowledge production framework, which provides the continuing growth in the intelligence education process. A recent change in intelligence education is the development of intelligence schools that combine theory and practice. Intelligence schools provide knowledge and instrumental orientation to future or current intelligence professionals.

Dr. Marrin noted that there are three different ways to bridge the gap between intelligence scholarship and intelligence practice. The first type of bridge is by individuals, people who Dr. Marrin terms 'in and outers.' These individuals might start in governments and then teach their knowledge in universities, or university professors might transition into government work. The second type of bridge is more institutionalized. This refers to intelligence studies programs within public policy schools, which provide platforms to produce and teach knowledge. The third type of bridge is a more stable and larger platform. These 
are intelligence studies centers at universities. They maximize the potential that a university has in intelligence production and provide a bridge between the informational and conceptual needs of the practitioner. These centers, however, are limited and more effectively done only in Britain.

Dr. Marrin concluded his presentation by noting that optimistically looking into the future, new mechanisms for bridging the gap between scholarship and practice can provide new and better ideas to improve intelligence. If something has not been developed to its full potential, we have the opportunity to set things in motion to improve the intelligence space. Intelligence studies is the contribution that higher education makes to interpret its past, understand its present, and forecast its future.

\section{Question Period}

Dr. Stephen Marrin reflected on his experiences as an 'in and outer' and proposed that internationalizing intelligence studies through journal publications is the most efficient way to increase generational, ethnic, and cultural diversity in the intelligence education space. This diversification in perspectives can be accomplished through targeted recruitment. Although it takes a large amount of work, it is crucial to reach out and engage people at the personal level to make it work. As for institutionalized diversification, it is a little more difficult to encourage diverse contributions when the scope is global and the decision to submit a paper is that of the individual.

Regarding essential skills and traits that successful analysts must possess, Dr. Marrin emphasized that reading and writing skills (as opposed to the use of technology) are critical because they lead to the acquisition of subject matter expertise.

\section{KEY POINTS OF DISCUSSION}

\section{Presentation}

- The nature of intelligence studies is an interdisciplinary approach that is not intrinsically instrumental but that can serve several purposes.

- One of the most prominent changes in the nature of intelligence is education 'about' intelligence.

- A recent change in intelligence education is the development of intelligence schools that combine theory and practice. 
- There are three different ways to bridge the gap between intelligence scholarship and intelligence practice: by individuals, by intelligence studies programs, and by intelligence studies centers.

- Intelligence studies is the contribution that higher education makes to interpret its past, understand its present, and forecast its future.

\section{Question Period}

- Increasing the diversity of authors and perspectives is key to satisfying the strategic agenda of internationalizing intelligence studies.

- Diversification in perspectives can be accomplished through targeted recruitment by engaging people at the personal level.

- Reading and writing skills are fundamental and critical for intelligence analysts.

(c) $(7)(9$

Commercial-NoDerivatives 4.0 International License.

(C) (STEPHEN MARRIN, 2022)

Published by the Journal of Intelligence, Conflict, and Warfare and Simon Fraser University

Available from: https://jicw.org/

The Journal of Intelligence, Conflict, and Warfare

Volume 4, Issue 3 